\title{
A phase I study to assess afatinib in combination with carboplatin or with carboplatin plus paclitaxel in patients with advanced solid tumors
}

\author{
Mary E. R. O'Brien ${ }^{1} \cdot$ Debashis Sarker $^{2} \cdot$ Jaishree Bhosle $^{1} \cdot$ Kiruthikah Thillai $^{2} \cdot$ Timothy A. Yap $^{1}$. \\ Martina Uttenreuther-Fischer ${ }^{3} \cdot$ Karine Pemberton $^{4} \cdot{\text { Xidong } \operatorname{~Jin}^{5}}^{5} \cdot$ Sabrina Wiebe $^{3} \cdot$ Johann de Bono $^{1} \cdot$ James Spicer $^{2}$
}

Received: 11 July 2018 / Accepted: 30 July 2018 / Published online: 7 August 2018

(c) The Author(s) 2018

\begin{abstract}
Purpose Afatinib, an irreversible ErbB family blocker, has demonstrated preclinical antitumor activity with chemotherapy. Methods As part of a phase I trial in patients with advanced solid tumors (NCT00809133; $3+3$ dose-escalation design), we determined the maximum tolerated dose (MTD) of afatinib with carboplatin (A/C) or with carboplatin plus paclitaxel (A/C/P). Starting doses: afatinib $20 \mathrm{mg} /$ day, carboplatin AUC6 (A/C) with paclitaxel $175 \mathrm{mg} / \mathrm{m}^{2}$ (A/C/P) (chemotherapy: Day 1 of 21-day cycles). The primary objective was to determine the MTDs; safety, pharmacokinetics and antitumor activity were also evaluated.

Results Thirty-eight patients received $\mathrm{A} / \mathrm{C}(n=12)$ or $\mathrm{A} / \mathrm{C} / \mathrm{P}(n=26)$. No dose-limiting toxicities (DLTs) were reported with $\mathrm{A}(20 \mathrm{mg}) / \mathrm{C}$ (AUC6). One patient experienced DLT in the A(40 mg)/C(AUC6) cohort (grade 3 acneiform rash); A(40 mg)/ C(AUC6) was determined as the recommended phase II dose (RP2D) for A/C. Two patients each had DLTs with A(20 mg/ day)/C(AUC6)/P(175 mg/m²): fatigue, infection, diarrhea, small intestine hemorrhage, dehydration, renal impairment, neutropenic sepsis $(n=1)$, mucositis $(n=1) ; \mathrm{A}(40 \mathrm{mg}) / \mathrm{C}(\mathrm{AUC} 5) / \mathrm{P}\left(175 \mathrm{mg} / \mathrm{m}^{2}\right)$ : febrile neutropenia $(n=1)$, mucositis, fatigue $(n=1)$; and $\mathrm{A}(30 \mathrm{mg}) / \mathrm{C}(\mathrm{AUC} 5) / \mathrm{P}\left(175 \mathrm{mg} / \mathrm{m}^{2}\right)$ : stomatitis $(n=1)$, mucositis $(n=1)$. No DLT was observed with $\mathrm{A}(20 \mathrm{mg}) / \mathrm{C}(\mathrm{AUC} 5) / \mathrm{P}\left(175 \mathrm{mg} / \mathrm{m}^{2}\right)$, determined as the RP2D for A/C/P. The most frequent drug-related adverse events were (A/C; A/C/P): rash $(75 \% ; 73 \%)$, fatigue $(67 \% ; 69 \%)$, and diarrhea $(58 \% ; 88 \%)$. Drug plasma concentrations were similar between cycles, suggesting no drug-drug interactions. Objective response rates in these heavily pretreated patients were $\mathrm{A} / \mathrm{C}, 3 / 12(25 \%) ; \mathrm{A} / \mathrm{C} / \mathrm{P}, 5 / 26(19 \%)$.

Conclusions Afatinib $40 \mathrm{mg} /$ day (approved monotherapy dose) with carboplatin AUC6, and afatinib $20 \mathrm{mg} /$ day with carboplatin AUC5 and paclitaxel $175 \mathrm{mg} / \mathrm{m}^{2}$ demonstrated manageable safety and antitumor activity. Afatinib $>20 \mathrm{mg} /$ day in the triple combination was not well tolerated.
\end{abstract}

Keywords Afatinib $\cdot$ Carboplatin $\cdot$ Paclitaxel $\cdot$ Phase I $\cdot$ Solid tumors

James Spicer

james.spicer@kcl.ac.uk

1 Royal Marsden NHS Foundation Trust, Downs Road, Sutton, UK

2 King's College London, Guy's Hospital, 3rd Floor Bermondsey Wing, London, UK

3 Boehringer Ingelheim International GmbH, Biberach, Germany

4 Boehringer Ingelheim Ltd, Bracknell, UK

5 Boehringer Ingelheim Pharmaceuticals, Inc., Ridgefield, CT, USA

\section{Introduction}

Afatinib is an irreversible ErbB family blocker, which binds covalently to the intracellular kinase domains of, and prevents signaling from, all kinase-active members of the ErbB family. It is, therefore, active against epidermal growth factor receptor (EGFR), human epidermal growth factor receptor 2 (HER2) and ErbB4, and indirectly inhibits transphosphorylation of the kinase-inactive ErbB3 [1]. As a single agent, afatinib is approved for the first-line treatment of advanced EGFR mutation-positive lung adenocarcinoma, having demonstrated improved progression-free survival (PFS) versus platinum-based chemotherapy in these patients 
$[2,3]$. In addition, afatinib was recently approved for the treatment of patients unselected for EGFR mutations with advanced squamous cell carcinoma of the lung following first-line chemotherapy, with activity superior to erlotinib in this setting [4].

Given their non-overlapping mechanisms of action, the addition of targeted therapies such as afatinib to existing chemotherapy regimens may improve outcomes in patients with advanced solid tumors. In vitro cell-based assays have shown greater efficacy with afatinib combined with paclitaxel than with single-agent treatment [5]. The combination of afatinib with paclitaxel or docetaxel in xenograft animal models has also demonstrated improved efficacy compared with single-agent therapy [6].

The clinical feasibility and tolerability of combining afatinib with paclitaxel, and with paclitaxel plus bevacizumab, were previously explored in earlier parts of this trial (a total of four drug combinations were assessed in patients with advanced solid tumors in this trial [NCT00809133]) $[5,7]$. Both of these earlier combination regimens demonstrated manageable safety profiles and antitumor activity at the maximum tolerated doses (MTDs). Here, we evaluated the combination of afatinib with carboplatin, and with carboplatin and paclitaxel, in patients with advanced solid tumors.

\section{Materials and methods}

\section{Patients}

Patients eligible for treatment had advanced, non-resectable and/or metastatic solid tumors suitable for treatment with either carboplatin or carboplatin and paclitaxel, and were recruited at two centers in the United Kingdom. Key eligibility criteria included age $\geq 18$ years; Eastern Cooperative Oncology Group performance status (ECOG PS) of 0 or 1; life expectancy of at least 3 months and adequate organ function (cardiac left ventricular function with resting ejection fraction $[\mathrm{LVEF}] \geq 50 \%$; absolute neutrophil count $\geq 1.5 \times 10^{9} / \mathrm{L}$ [ $>2.0 \times 10^{9} / \mathrm{L}$ for patients allocated to carboplatin]; platelets $\geq 100,000 / \mu \mathrm{L}$; total bilirubin $\leq 26 \mu \mathrm{mol} / \mathrm{L}$; aspartate aminotransferase and/or alanine aminotransferase $\leq 2.5$ times the upper limit of normal; creatinine $\leq 132 \mu \mathrm{mol} / \mathrm{L}$ and creatinine clearance $>60 \mathrm{~mL} / \mathrm{min}$ by Cockcroft-Gault equation).

Exclusion criteria included gastrointestinal tract disease that could impair drug absorption; significant cardiovascular disease; active infectious disease; known interstitial lung disease; untreated or symptomatic brain metastases; persistent grade $\geq 2$ neuropathy or neurotoxicity from any cause; and treatment with chemotherapy, immunotherapy, radiotherapy, biologic therapy, hormone therapy, EGFR- or
HER2-targeting drugs or other investigational drugs within 4 weeks prior to starting trial medication.

The study was conducted in accordance with the Declaration of Helsinki and Good Clinical Practice, and ethical approval was provided by the UK Integrated Research Application System. All patients provided written informed consent.

\section{Study design and treatment}

A phase I open-label trial assessed four different drug combinations using a $3+3$ dose-escalation design (NCT00809133); previous analyses of other combination regimens included in the trial have been reported $[5,7]$. In this report, afatinib was evaluated in combination with carboplatin (A/C) or carboplatin plus paclitaxel (A/C/P). In both combinations, oral afatinib was administered once daily, beginning on Day 2 of Cycle 1 in 21-day cycles, at a starting dose of $20 \mathrm{mg} / \mathrm{day}$, and escalated to $40 \mathrm{mg}$ (the approved monotherapy starting dose) and then $50 \mathrm{mg}$ in subsequent dose cohorts. Chemotherapy was administered intravenously on Day 1 of each 21-day cycle: carboplatin at a dose targeting an area under the concentration-time curve of $6 \mathrm{mg} / \mathrm{mL}$.min (AUC6), and paclitaxel at $175 \mathrm{mg} / \mathrm{m}^{2}$ (carboplatin was administered after paclitaxel, consistent with standard medical practice in the United Kingdom) [8]. Target doses for carboplatin were calculated using the Calvert formula (dose $[\mathrm{mg}]=$ target AUC $[\mathrm{mg} / \mathrm{mL} \cdot \mathrm{min}] \times$ (glomerular filtration rate [GFR; $\mathrm{mL} / \mathrm{min}]+25 \mathrm{~mL} / \mathrm{min})$ ). Based on the American Society for Clinical Oncology guidelines, the GFR used in the Calvert formula was capped at $125 \mathrm{~mL} / \mathrm{min}$ [9]. In the event of toxicity with carboplatin AUC6, a dose reduction to AUC5 was allowed. Patients continued combination treatment for six cycles or until tumor progression, intolerable adverse events (AEs) or withdrawal of consent. Patients with clinical benefit after six cycles could continue either with combination treatment or single-agent afatinib.

The primary endpoint was safety, assessed as doselimiting toxicities (DLTs) to define the MTD of the two afatinib-chemotherapy combinations. MTD was defined as the highest dose of afatinib in combination with carboplatin, or with carboplatin and paclitaxel, at which no more than one of six patients experienced a DLT during Cycle 1. To be evaluable for determination of the MTD, patients must have completed the first 2 weeks of therapy or have experienced a DLT; patients who did not meet either of these criteria were replaced within the respective dose cohort. Secondary endpoints included pharmacokinetic parameters and antitumor activity (objective tumor responses [OR]). 


\section{Assessments}

All patients were assessed for AEs according to the National Cancer Institute Common Terminology Criteria for Adverse Events (NCI CTCAE, version 3.0); relationship to study treatment was assessed by the investigators.

DLTs were defined as any of the following drugrelated AEs: grade 4 uncomplicated neutropenia (i.e., fever $\leq 38.3^{\circ} \mathrm{C}$ ) for $>7$ days; neutropenia associated with fever $>38.5^{\circ} \mathrm{C}$; platelets $<25 \times 10^{9} / \mathrm{L}$ or grade 3 thrombocytopenia associated with bleeding requiring transfusion; grade $\geq 2$ decrease in LVEF; uncontrolled hypertension despite multiple anti-hypertension therapies; grade $\geq 2$ worsening of renal function; grade $>2$ diarrhea despite anti-diarrheal treatment; persistent grade $\geq 2$ diarrhea for $\geq 7$ days despite supportive care; grade $>2$ nausea and/or vomiting despite antiemetic treatment; persistent grade $\geq 2$ vomiting for $\geq 7$ days despite supportive care; and all other non-hematologic toxicities of grade $\geq 3$, except incompletely treated nausea, vomiting or diarrhea.

For the assessment of pharmacokinetic parameters of afatinib $\left(\mathrm{AUC}_{\tau, \mathrm{ss}}\right.$ and $\left.C_{\text {max }, \mathrm{ss}}\right)$, total platinum $\left(\mathrm{AUC}_{0-24}\right.$ and $\left.C_{\max }\right)$ and paclitaxel $\left(\mathrm{AUC}_{0-23}\right.$ and $C_{\max }$ ), blood was collected on Days 1 and 2 of Cycles 1 and 2. Samples were taken pre- and post- $(1.0,1.5,2.0,3.0,4.0,6.0,8.0$ and $24.0 \mathrm{~h}$ ) carboplatin infusion (in the $\mathrm{A} / \mathrm{C}$ arm) and preand post- $(1.0,2.0,3.0,3.5,4.0,4.5,5.0,6.0,8.0,9.0$ and $24.0 \mathrm{~h}$ ) paclitaxel infusion (in the $\mathrm{A} / \mathrm{C} / \mathrm{P}$ arm). Of note, the 1.0- and 2.0-h time points post-paclitaxel infusion were conducted only during Cycle 2. A sample was also collected on Day 15 of Cycle 1 before the administration of afatinib in both treatment combinations. Plasma concentrations of afatinib and paclitaxel were analyzed by a validated high-performance liquid chromatography-tandem mass spectrometry method at Boehringer Ingelheim (Biberach, Germany) and Nuvisan GmbH (Neu-Ulm, Germany), respectively. Concentrations of total platinum (from carboplatin) were determined by a validated inductively coupled plasma/mass spectrometry assay at Nuvisan GmbH (Neu-Ulm, Germany).

Tumor assessments were performed by the investigators at screening and every 6 weeks after the start of treatment until progressive disease (PD) according to Response Evaluation Criteria in Solid Tumors (RECIST, version 1.0).

\section{Statistical analysis}

AEs and antitumor activity were assessed in all patients who received at least one dose of afatinib. All analyses in this trial were descriptive and exploratory.

\section{Results}

\section{Patients and treatment exposure}

Thirty-eight patients were treated in the trial, with the most common tumor type (A/C, 58\%; A/C/P, 65\%) being nonsmall cell lung cancer (NSCLC). Additional baseline demographics and disease characteristics are shown in Table 1. Twelve patients received the combination of $\mathrm{A} / \mathrm{C}$ and 26 received A/C/P. In the A/C arm, 10 (83\%) patients completed at least one cycle and $6(50 \%)$ patients completed at least six cycles of treatment; all patients discontinued study treatment due to PD. In the A/C/P arm, 24 (92\%) patients completed at least one cycle and $11(42 \%)$ patients completed at least six cycles of treatment. The primary reason for termination of study treatment in the $\mathrm{A} / \mathrm{C} / \mathrm{P}$ arm was $\mathrm{PD}$ in 21 patients (81\%) and AEs, including DLTs, in 5 patients (19\%). Median treatment duration was 106 days (range 13-390) for $\mathrm{A} / \mathrm{C}$ and 85 days (range 6-401) for $\mathrm{A} / \mathrm{C} / \mathrm{P}$.

\section{MTD assessment}

In the $\mathrm{A} / \mathrm{C}$ arm, nine patients were evaluable for the determination of MTD (Fig. 1a; Table 2). In Cohort 1 (afatinib $20 \mathrm{mg}$ plus carboplatin AUC6), three patients received combination treatment and no DLTs were reported. In Cohort 2 (afatinib $40 \mathrm{mg}$ plus carboplatin AUC6), no DLTs were reported in the first three evaluable patients (two patients were not evaluable for MTD determination and were replaced), and the cohort was expanded to nine patients (one patient was not evaluable and was replaced). Of the six patients who were evaluable for MTD in Cohort 2, one experienced a DLT (grade 3 acneiform rash). The afatinib dose, here combined with a dose of carboplatin, was not further escalated from the standard monotherapy dose of $40 \mathrm{mg}$, consistent with standard of care. Afatinib $40 \mathrm{mg}$ plus carboplatin AUC6 was defined as the recommended phase II dose (RP2D) in the A/C arm, without an MTD being reached.

In the $\mathrm{A} / \mathrm{C} / \mathrm{P}$ arm, 23 of 26 patients were evaluable for assessment of the MTD (Fig. 1b; Table 2). Of the seven patients who received treatment in Cohort 1 (afatinib $20 \mathrm{mg}$ plus carboplatin AUC6 plus paclitaxel $175 \mathrm{mg} / \mathrm{m}^{2}$ ), six were evaluable for MTD and two had DLTs, which included grade 3 neutropenic sepsis with Clostridium difficile diarrhea in one patient and grade 3 mucositis in the other patient (Table 2). The carboplatin dose was decreased to AUC5 in Cohort 2 (afatinib $20 \mathrm{mg}$ plus carboplatin AUC5 plus paclitaxel $175 \mathrm{mg} / \mathrm{m}^{2}$ ), in which three patients received treatment and no DLTs were reported. The afatinib dose was then increased to $40 \mathrm{mg}$ in Cohort 3 (afatinib $40 \mathrm{mg}$ plus carboplatin AUC5 plus paclitaxel $175 \mathrm{mg} / \mathrm{m}^{2}$ ), and five patients received 
Table 1 Patient demographics at baseline

\begin{tabular}{|c|c|c|}
\hline & $\mathrm{A} / \mathrm{C}(n=12)$ & $\mathrm{A} / \mathrm{C} / \mathrm{P}(n=26)$ \\
\hline \multicolumn{3}{|l|}{ Age, years } \\
\hline Median (range) & $57.5(35-80)$ & $60.5(26-73)$ \\
\hline \multicolumn{3}{|l|}{ Gender, $n(\%)$} \\
\hline Male & $8(67)$ & $13(50)$ \\
\hline Female & $4(33)$ & $13(50)$ \\
\hline \multicolumn{3}{|l|}{ Race, $n(\%)$} \\
\hline White & $8(67)$ & $23(88)$ \\
\hline Black & $2(17)$ & $1(4)$ \\
\hline Asian & $2(17)$ & $2(8)$ \\
\hline \multicolumn{3}{|l|}{ ECOG PS, $n(\%)$} \\
\hline 0 & 0 & $2(8)$ \\
\hline 1 & $12(100)$ & $23(88)$ \\
\hline 2 & 0 & $1(4)^{a}$ \\
\hline \multicolumn{3}{|c|}{ Time from first histologic diagnosis, years } \\
\hline Median (range) & $1.5(0.7-6.3)$ & $1.9(0.7-6.6)$ \\
\hline \multicolumn{3}{|l|}{ Tumor type, $n(\%)$} \\
\hline NSCLC & $7(58)$ & $17(65)$ \\
\hline Pancreas & $1(8)$ & $3(12)$ \\
\hline Gastrointestinal tract & $2(17)$ & 0 \\
\hline Breast & 0 & $2(8)$ \\
\hline Other $^{\mathrm{b}}$ & $2(17)$ & $4(15)$ \\
\hline \multicolumn{3}{|c|}{ Patients with previous anti-cancer therapy, $n(\%)$} \\
\hline Surgery & $5(42)$ & $11(42)$ \\
\hline Systemic chemotherapy & $12(100)$ & $26(100)$ \\
\hline Immunotherapy & $1(8)$ & $1(4)$ \\
\hline Hormone therapy & $0(0)$ & $1(4)$ \\
\hline Radiotherapy & $6(50)$ & $13(50)$ \\
\hline Other (including biologic therapy) & $7(58)$ & $6(23)$ \\
\hline
\end{tabular}

$A / C$ afatinib plus carboplatin, $A / C / P$ afatinib plus carboplatin plus paclitaxel, ECOG PS Eastern Cooperative Oncology Group performance status; NSCLC non-small cell lung cancer

${ }^{a}$ ECOG PS declined between screening and baseline; baseline visit was 2 days after the screening visit for this patient

${ }^{\mathrm{b}}$ Esophageal $(n=1)$ and ovarian cancer $(n=1)$ in the $\mathrm{A} / \mathrm{C}$ arm, adrenal $(n=1)$, biliary tree $(n=1)$, bladder $(n=1)$ and endometrial cancer $(n=1)$ in the $\mathrm{A} / \mathrm{C} / \mathrm{P}$ arm

treatment and were evaluable for MTD; two patients had DLTs (grade 3 fatigue and grade 3 mucositis in one patient; grade 3 febrile neutropenia in another). Owing to the DLTs observed, an intermediate afatinib dose of $30 \mathrm{mg}$ was explored in Cohort 4 (afatinib $30 \mathrm{mg}$ plus carboplatin AUC5 plus paclitaxel $175 \mathrm{mg} / \mathrm{m}^{2}$ ). Eight patients received this treatment and, of the six patients evaluable for MTD, two reported DLTs (grade 3 stomatitis; grade 3 mucositis). The next lower dose level (afatinib $20 \mathrm{mg}$ plus carboplatin AUC5 plus paclitaxel $175 \mathrm{mg} / \mathrm{m}^{2}$ ) was then expanded with three patients, in addition to the three patients already treated with these doses in Cohort 2, and no DLTs were reported. Thus, afatinib $20 \mathrm{mg}$ was identified as the MTD in combination with carboplatin AUC5 and paclitaxel $175 \mathrm{mg} / \mathrm{m}^{2}$. This dose was also identified as the RP2D for the A/C/P combination.

\section{Adverse events}

The most frequent drug-related AEs of any grade in the A/C arm were rash (grouped term; $n=9,75 \%$ ), which was most commonly acneiform, fatigue $(n=8,67 \%)$ and diarrhea $(n=7,58 \%)$. Most AEs were of CTCAE grade 1 or 2 in intensity (Table 3), and the only non-hematologic treatmentrelated grade 3 AEs in this arm were rash, fatigue and diarrhea (one patient each; $8 \%$ ). There were no treatment-related grade $\geq 4$ AEs.

The most frequent drug-related AEs in the A/C/P arm were diarrhea $(n=23,88 \%)$, rash (grouped term; $n=19$, $73 \%)$ and fatigue $(n=18,69 \%)$. Most AEs were of CTCAE grade 1 or 2 in intensity, and there were no grade $\geq 4$ treatment-related AEs (Table 4). The most common nonhematologic treatment-related grade 3 AEs in this arm 
Fig. 1 Dose-escalation schema and incidence of DLTs in the $\mathrm{A} / \mathrm{C}$ arm (a) and the $\mathrm{A} / \mathrm{C} / \mathrm{P}$ arm (b). $A 20+C 6$, afatinib 20 $\mathrm{mg}$ /day + carboplatin AUC6; $A 40+C 6$, afatinib $40 \mathrm{mg} /$ day + carboplatin AUC6; A20 + $P 175+C 5$, afatinib $20 \mathrm{mg} /$ day + paclitaxel $175 \mathrm{mg} / \mathrm{m}^{2}$ + carboplatin AUC5; A20 + $P 175+C 6$, afatinib $20 \mathrm{mg} /$ day + paclitaxel $175 \mathrm{mg} / \mathrm{m}^{2}$ + carboplatin AUC6; $A 30$ + $P 175+C 5$, afatinib $30 \mathrm{mg} /$ day + paclitaxel $175 \mathrm{mg} / \mathrm{m}^{2}$ + carboplatin AUC5; $A 40$ + $P 175+C 5$, afatinib $40 \mathrm{mg} /$ day + paclitaxel $175 \mathrm{mg} / \mathrm{m}^{2}+$ carboplatin AUC5 a

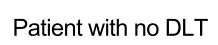

Patient with DLT

Patient not evaluable

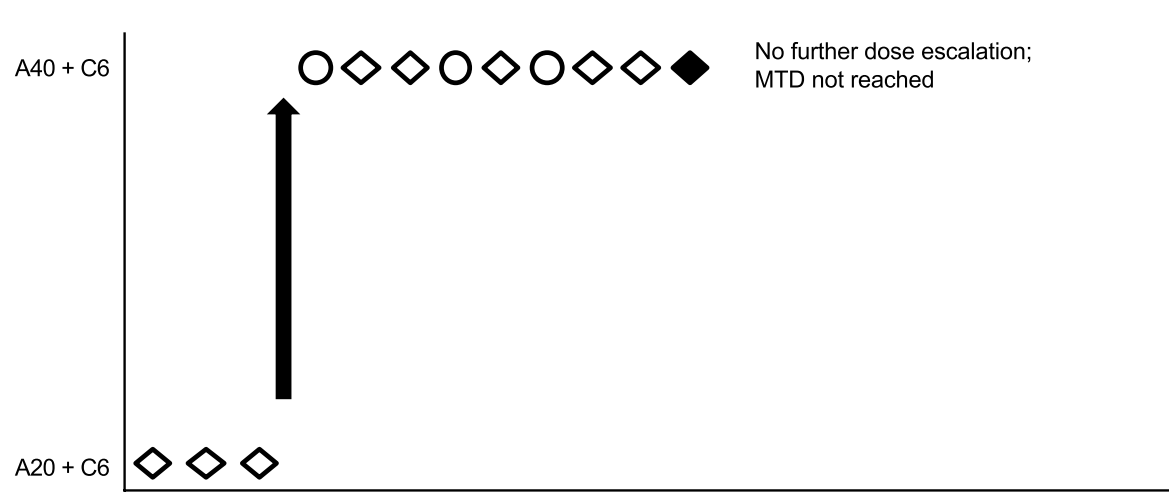

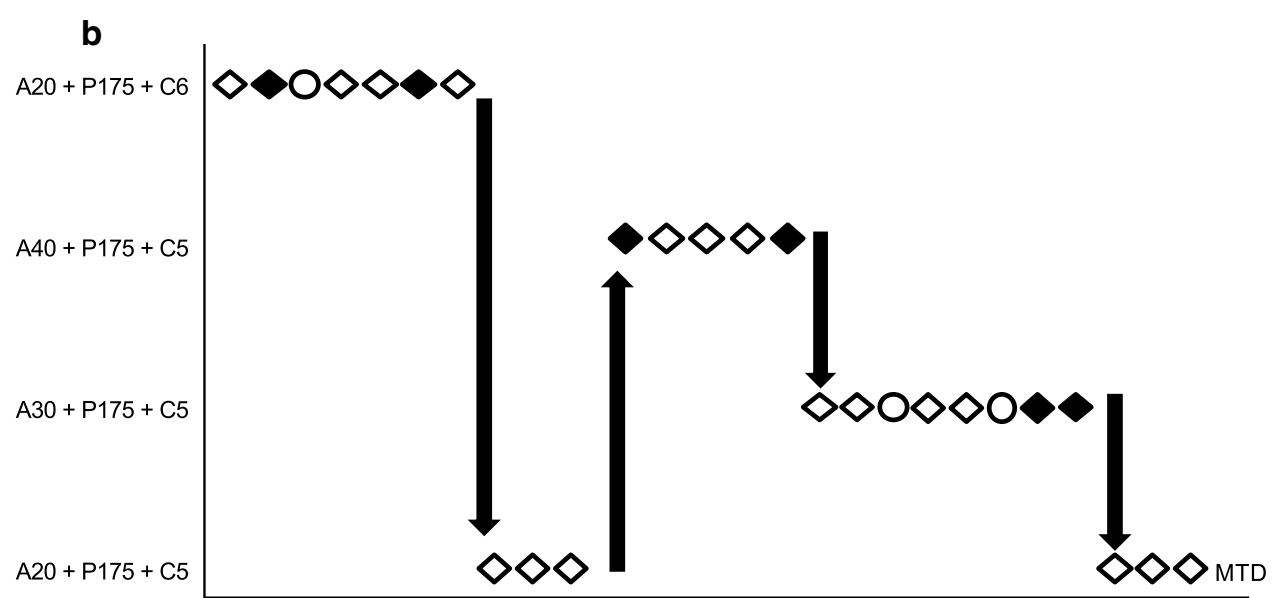

were mucositis $(n=4 ; 15 \%)$ and fatigue $(n=3 ; 12 \%)$. Seven (27\%) patients, including one patient with Clostridium difficile infection and one patient with mucositis (discussed above as DLTs), had AEs leading to discontinuation of study treatment.

\section{Pharmacokinetics}

Table 5 summarizes key pharmacokinetic parameters for the RP2D cohorts of both treatment arms. Total platinum and paclitaxel showed a comparable exposure, based on $C_{\max }$ and AUC, in the absence and presence of afatinib, suggesting no clinically relevant effect of afatinib on the pharmacokinetic parameters of these drugs. Afatinib reached peak plasma concentration $1-4 \mathrm{~h}$ after administration in the $\mathrm{A} / \mathrm{C}$ arm and $3-8 \mathrm{~h}$ after administration in the $\mathrm{A} / \mathrm{C} / \mathrm{P}$ arm.

\section{Antitumor activity}

In the $\mathrm{A} / \mathrm{C}$ arm, three patients (25\%) had a confirmed partial response (PR), five (42\%) had stable disease (SD) and one $(8 \%)$ had PD; three patients $(25 \%)$ were not evaluable for tumor response. Five patients (42\%) achieved disease control (PR or SD) for at least 6 months. No ORs were seen in the seven patients with NSCLC receiving A/C treatment, but four patients (57\%) had a best response of SD, one (14\%) for at least 6 months. A response duration of 10.2 months was seen in one patient with a gastrointestinal neuroendocrine tumor.

In the $\mathrm{A} / \mathrm{C} / \mathrm{P}$ arm, five patients (19\%) had a confirmed PR, eleven (42\%) had SD and six (23\%) had PD; four patients (15\%) were not evaluable for tumor response. Of the 17 patients with NSCLC treated with A/C/P, ORs were reported for three patients (18\%), and eight (47\%) had SD. Four patients (15\%), all of whom had NSCLC, achieved disease control (PR or SD) for at least 6 months. A response duration of 10.5 months was seen in one patient with NSCLC.

\section{Discussion}

In this phase I study, we assessed the safety and preliminary antitumor activity of afatinib in combination with carboplatin, and with carboplatin plus paclitaxel. In the A/C 
Table 2 DLTs (related to study drug) in Cycle 1 by dose cohort

\begin{tabular}{|c|c|c|c|c|c|}
\hline \multicolumn{2}{|l|}{$\mathrm{A} / \mathrm{C}$} & \multicolumn{4}{|l|}{$\mathrm{A} / \mathrm{C} / \mathrm{P}$} \\
\hline $\begin{array}{l}\mathrm{A}(20 \mathrm{mg})+\mathrm{C} \\
(\mathrm{AUC6})(n=3)\end{array}$ & $\begin{array}{l}\mathrm{A}(40 \mathrm{mg})+\mathrm{C} \\
(\mathrm{AUC6})(n=9)\end{array}$ & $\begin{array}{l}\mathrm{A}(20 \mathrm{mg})+\mathrm{C} \\
(\mathrm{AUC} 6)+\mathrm{P} \\
\left(175 \mathrm{mg} / \mathrm{m}^{2}\right)(n=7)\end{array}$ & $\begin{array}{l}\mathrm{A}(20 \mathrm{mg})+\mathrm{C} \\
(\mathrm{AUC} 5)+\mathrm{P} \\
\left(175 \mathrm{mg} / \mathrm{m}^{2}\right)(n=6)\end{array}$ & $\begin{array}{l}\mathrm{A}(40 \mathrm{mg})+\mathrm{C} \\
(\mathrm{AUC} 5)+\mathrm{P} \\
\left(175 \mathrm{mg} / \mathrm{m}^{2}\right)(n=5)\end{array}$ & $\begin{array}{l}\mathrm{A}(30 \mathrm{mg})+\mathrm{C} \\
(\mathrm{AUC} 5)+\mathrm{P}(175 \mathrm{mg} / \\
\left.\mathrm{m}^{2}\right)(n=8)\end{array}$ \\
\hline 3 & 6 & 6 & 6 & 5 & 6 \\
\hline 0 & 1 & 2 & 0 & 2 & 2 \\
\hline 0 & 0 & 2 & 0 & 0 & 0 \\
\hline
\end{tabular}

\begin{tabular}{|c|c|c|c|c|c|c|}
\hline $\begin{array}{l}\text { Patients evaluable } \\
\text { for MTD }\end{array}$ & 3 & 6 & 6 & 6 & 5 & 6 \\
\hline Patients with a DLT & 0 & 1 & 2 & 0 & 2 & 2 \\
\hline $\begin{array}{l}\text { DLTs leading to } \\
\text { permanent discon- } \\
\text { tinuation of study } \\
\text { treatment }\end{array}$ & 0 & 0 & 2 & 0 & 0 & 0 \\
\hline \multicolumn{7}{|l|}{ DLTs, $n$} \\
\hline Acneiform rash ${ }^{\mathrm{a}}$ & 0 & 1 & 0 & 0 & 0 & 0 \\
\hline Mucositis $^{b}$ & 0 & 0 & 1 & 0 & 1 & 1 \\
\hline Fatigue & 0 & 0 & 1 & 0 & 1 & 0 \\
\hline Infection & 0 & 0 & 1 & 0 & 0 & 0 \\
\hline Dehydration & 0 & 0 & 1 & 0 & 0 & 0 \\
\hline Diarrhea & 0 & 0 & 1 & 0 & 0 & 0 \\
\hline $\begin{array}{l}\text { Febrile neutrope- } \\
\text { nia/neutropenic } \\
\text { sepsis }^{\mathrm{d}}\end{array}$ & 0 & 0 & 1 & 0 & 1 & 0 \\
\hline Renal impairment & 0 & 0 & 1 & 0 & 0 & 0 \\
\hline $\begin{array}{l}\text { Small intestinal } \\
\text { hemorrhage }\end{array}$ & 0 & 0 & 1 & 0 & 0 & 0 \\
\hline Stomatitis & 0 & 0 & 0 & 0 & 0 & 1 \\
\hline
\end{tabular}

$A / C$ afatinib plus carboplatin, $A / C / P$ afatinib plus carboplatin plus paclitaxel, $A U C 5$ area under the concentration-time curve of $5 \mathrm{mg} / \mathrm{mL}$ min, AUC6 area under the concentration-time curve of $6 \mathrm{mg} / \mathrm{mL} \mathrm{min}, D L T$ dose-limiting toxicity, $M T D$ maximum tolerated dose

aPreferred term: dermatitis acneiform

${ }^{\mathrm{b}}$ Preferred term: mucosal inflammation

${ }^{\mathrm{c}}$ Clostridium difficile

${ }^{\mathrm{d}}$ Includes one patient with febrile neutropenia and one patient with neutropenic sepsis

arm, dose escalation was not continued beyond afatinib $40 \mathrm{mg} /$ day plus carboplatin AUC6 and so an MTD was not reached. The standard dose for afatinib monotherapy is $40 \mathrm{mg} /$ day $[10,11]$. Since manageable safety and antitumor activity were observed at this dose level with carboplatin AUC6, and no drug-drug interactions were observed, the RP2D was determined as afatinib $40 \mathrm{mg}$ plus carboplatin AUC6. In the A/C/P arm, the MTD and RP2D were determined to be afatinib $20 \mathrm{mg}$ plus carboplatin AUC5 plus paclitaxel $175 \mathrm{mg} / \mathrm{m}^{2}$. For this triplet combination, the afatinib single-agent dose needed to be de-escalated (from 40 to $20 \mathrm{mg}$ ) for the regimen to be tolerated. In both treatment combinations, afatinib at the RP2D was associated with a manageable safety profile. The most common drug-related AEs were rash, fatigue and diarrhea, and the majority of these were grade 1 or 2 in intensity. The AE profiles of the combinations were in line with the known individual safety profiles of afatinib, carboplatin and paclitaxel $[5,10,12-12]$.
Afatinib pharmacokinetic parameters were consistent with earlier studies of afatinib as a single agent $[13,14]$ and in combination [7], suggesting carboplatin and paclitaxel did not influence absorption and plasma concentrations of afatinib. Similarly, total platinum (from carboplatin) and paclitaxel plasma concentrations were similar in the absence and presence of afatinib, suggesting there were no relevant interactions between afatinib and paclitaxel and/or carboplatin in this study.

Evidence of antitumor activity was observed with both the $\mathrm{A} / \mathrm{C}$ and $\mathrm{A} / \mathrm{C} / \mathrm{P}$ combinations. $\mathrm{A} / \mathrm{C}$ was associated with disease control (PR or SD) in eight patients (67\%), while disease control was observed in 16 patients $(62 \%)$ receiving $\mathrm{A} / \mathrm{C} / \mathrm{P}$. In this study, $58 \%$ and $65 \%$ of patients in the $\mathrm{A} / \mathrm{C}$ and $\mathrm{A} / \mathrm{C} / \mathrm{P}$ arms, respectively, had NSCLC. Of these pretreated NSCLC patients, more than half in each treatment combination had disease control $(57 \%$ in the $\mathrm{A} / \mathrm{C}$ arm and $65 \%$ in the $\mathrm{A} / \mathrm{C} / \mathrm{P}$ arm), with $18 \%$ achieving an $\mathrm{OR}$ in the $\mathrm{A} / \mathrm{C} / \mathrm{P}$ arm. Of note, a response in one patient with 
Table 3 Treatment-related AEs in at least $10 \%$ of total patients in the $\mathrm{A} / \mathrm{C}$ arm

\begin{tabular}{|c|c|c|c|c|c|c|}
\hline \multirow[t]{2}{*}{ AEs } & \multicolumn{2}{|c|}{$\begin{array}{l}\text { A }(20 \mathrm{mg})+\mathrm{C}(\mathrm{AUC6}) \\
(n=3), n\end{array}$} & \multicolumn{2}{|c|}{$\begin{array}{l}\text { A }(40 \mathrm{mg})+\mathrm{C}(\mathrm{AUC} 6) \\
(n=9), n\end{array}$} & \multicolumn{2}{|c|}{ Total $(n=12), n(\%)$} \\
\hline & All grades & Grade $3^{a}$ & All grades & Grade $3^{a}$ & All grades & Grade $3^{a}$ \\
\hline Any AE & 3 & 0 & 9 & 3 & $12(100)$ & $3(25)$ \\
\hline $\operatorname{Rash}^{+}$ & 2 & 0 & 7 & 1 & $9(75)$ & $1(8)$ \\
\hline Fatigue & 3 & 0 & 5 & 1 & $8(67)$ & $1(8)$ \\
\hline Diarrhea & 1 & 0 & 6 & 1 & $7(58)$ & $1(8)$ \\
\hline Nausea/vomiting $^{+}$ & 1 & 0 & 5 & 0 & $6(50)$ & 0 \\
\hline Anorexia $^{\mathrm{b}}$ & 1 & 0 & 3 & 0 & $4(33)$ & 0 \\
\hline Thrombocytopenia & 1 & 0 & 2 & 0 & $3(25)$ & 0 \\
\hline Epistaxis & 0 & 0 & 3 & 0 & $3(25)$ & 0 \\
\hline Oropharyngeal pain & 0 & 0 & 3 & 0 & $3(25)$ & 0 \\
\hline Stomatitis & 0 & 0 & 2 & 0 & $2(17)$ & 0 \\
\hline Rhinitis & 0 & 0 & 2 & 0 & $2(17)$ & 0 \\
\hline Taste change $^{c}$ & 1 & 0 & 1 & 0 & $2(17)$ & 0 \\
\hline Dry skin & 0 & 0 & 2 & 0 & $2(17)$ & 0 \\
\hline Weight loss ${ }^{\mathrm{d}}$ & 1 & 0 & 1 & 0 & $2(17)$ & 0 \\
\hline Nasal inflammation & 0 & 0 & 2 & 0 & $2(17)$ & 0 \\
\hline
\end{tabular}

$A / C$ afatinib plus carboplatin, $A E$ adverse event, $A U C 6$ area under the concentration-time curve of $6 \mathrm{mg} /$ $\mathrm{mL} \min$

${ }^{+}$Grouped term (rash included reported preferred terms of folliculitis, cellulitis, dermatitis acneiform and rash; nausea/vomiting included reported preferred terms of nausea and vomiting)

${ }^{a}$ There were no treatment-related grade 4 or 5 events

${ }^{b}$ Preferred term: decreased appetite

${ }^{\mathrm{c}}$ Preferred term: dysgeusia

${ }^{\mathrm{d}}$ Preferred term: weight decreased
NSCLC in the A/C/P combination arm was maintained for 10.5 months.

Several randomized trials have evaluated the potential clinical activity of the combination of EGFR-targeted agents with chemotherapy in advanced cancers, particularly NSCLC. Phase III studies in the first-line NSCLC setting in populations unselected for EGFR mutation have shown varying degrees of clinical efficacy for EGFR-targeted agent-chemotherapy combinations versus chemotherapy alone [15-17]. In the phase III TRIBUTE trial, 1059 treatment-naïve patients with NSCLC were randomized to first-line carboplatin and paclitaxel combined with either erlotinib or placebo. No survival benefit was observed with erlotinib plus chemotherapy versus placebo plus chemotherapy in the overall trial population; however, a substantial prolongation of survival was observed in the 'never smoked' subgroup (22.5 vs 10.1 months; hazard ratio [HR] 0.49, 95\% confidence interval [CI] 0.28-0.85; $p=0.01$ ) [15]. Similarly, in the phase III TALENT trial, 1172 treatment-naïve patients with NSCLC were randomized to first-line gemcitabine and cisplatin combined with either erlotinib or placebo, with no survival benefit observed in the erlotinib group. In a small subgroup of patients who 'never smoked', overall survival (OS) and PFS were increased with chemotherapy and erlotinib, compared to chemotherapy alone [16]. In contrast to the TALENT and TRIBUTE studies, the phase III FAST-ACT2 trial, conducted primarily in Asia, demonstrated significantly improved PFS (HR $0.57,95 \%$ CI $0.47-0.69 ; p<0.0001$ ) and OS (HR 0.79, 95\% CI 0.64-0.99; $p=0.0420$ ) with first-line chemotherapy (gemcitabine and platinum; Days 1 and 8 of a 4-week cycle) plus erlotinib (Days 15-28 of each cycle) over chemotherapy alone in 451 treatment-naïve patients with NSCLC. Benefit was primarily shown in those with EGFR mutation-positive disease; however, tumor samples were available in only $53 \%$ of the intent-to-treat population [17].

The combination of EGFR-targeted agents with chemotherapy has also been explored in the relapsed/refractory NSCLC setting. A randomized, phase II study in 165 patients with non-squamous NSCLC previously treated with one prior platinum-based chemotherapy regimen showed that pemetrexed plus erlotinib significantly improved PFS, OS and time to treatment failure versus pemetrexed alone; however, the combination was associated with an increase in grade 3/4 AEs [18]. We have previously reported on the combination of afatinib and weekly paclitaxel in patients with advanced solid tumors [5]. This regimen has since been assessed in a phase III trial of patients with relapsed/ 
Table 4 Treatment-related AEs in at least $10 \%$ of total patients in the A/C/P arm

\begin{tabular}{|c|c|c|c|c|c|c|c|c|c|c|}
\hline \multirow[t]{2}{*}{ AEs } & \multicolumn{2}{|c|}{$\begin{array}{l}\mathrm{A}(20 \mathrm{mg})+\mathrm{C} \\
(\mathrm{AUC} 6)+\mathrm{P}(175 \mathrm{mg} / \\
\left.\mathrm{m}^{2}\right)(n=7), n\end{array}$} & \multicolumn{2}{|c|}{$\begin{array}{l}\mathrm{A}(20 \mathrm{mg})+\mathrm{C} \\
(\mathrm{AUC} 5)+\mathrm{P}(175 \mathrm{mg} / \\
\left.\mathrm{m}^{2}\right)(n=6), n\end{array}$} & \multicolumn{2}{|c|}{$\begin{array}{l}\mathrm{A}(40 \mathrm{mg})+\mathrm{C} \\
(\mathrm{AUC} 5)+\mathrm{P}(175 \mathrm{mg} / \\
\left.\mathrm{m}^{2}\right)(n=5), n\end{array}$} & \multicolumn{2}{|c|}{$\begin{array}{l}\mathrm{A}(30 \mathrm{mg})+\mathrm{C} \\
(\mathrm{AUC} 5)+\mathrm{P}(175 \mathrm{mg} / \\
\left.\mathrm{m}^{2}\right)(n=8), n\end{array}$} & \multicolumn{2}{|c|}{ Total $(n=26), n(\%)$} \\
\hline & All grades & Grade $3 a$ & All grades & Grade 3a & All grades & Grade 3a & All grades & Grade $3 a$ & All grades & Grade $3^{\mathrm{a}}$ \\
\hline Any AE & 7 & 3 & 6 & 2 & 5 & 4 & 7 & 3 & $25(96)$ & $12(46)$ \\
\hline Diarrhea & 6 & 1 & 6 & 0 & 5 & 0 & 6 & 0 & $23(88)$ & $1(4)$ \\
\hline $\operatorname{Rash}^{+}$ & 2 & 0 & 5 & 0 & 5 & 0 & 7 & 0 & $19(73)$ & 0 \\
\hline Fatigue & 5 & 1 & 4 & 0 & 5 & 2 & 4 & 0 & $18(69)$ & $3(12)$ \\
\hline Mucositis $^{\mathrm{b}}$ & 3 & 1 & 2 & 0 & 3 & 1 & 4 & 2 & $12(46)$ & $4(15)$ \\
\hline Anorexia $^{c}$ & 4 & 0 & 1 & 0 & 3 & 0 & 2 & 0 & $10(38)$ & 0 \\
\hline Dry skin & 2 & 0 & 2 & 0 & 1 & 0 & 3 & 0 & $8(31)$ & 0 \\
\hline Nausea/vomiting+ & 4 & 0 & 0 & 0 & 1 & 0 & 3 & 0 & $8(31)$ & 0 \\
\hline Stomatitis & 0 & 0 & 3 & 1 & 3 & 0 & 1 & 1 & $7(27)$ & $2(8)$ \\
\hline Thrombocytopenia & 2 & 2 & 2 & 2 & 1 & 0 & 1 & 0 & $6(23)$ & $4(15)$ \\
\hline Peripheral neuropathy & 1 & 0 & 2 & 0 & 0 & 0 & 3 & 0 & $6(23)$ & 0 \\
\hline Abdominal pain & 4 & 0 & 0 & 0 & 1 & 0 & 1 & 0 & $6(23)$ & 0 \\
\hline Neutropenia & 1 & 1 & 3 & 2 & 1 & 1 & 0 & 0 & $5(19)$ & $4(15)$ \\
\hline Epistaxis & 2 & 0 & 1 & 0 & 1 & 0 & 1 & 0 & $5(19)$ & 0 \\
\hline Nasal inflammation & 0 & 0 & 2 & 0 & 3 & 0 & 0 & 0 & $5(19)$ & 0 \\
\hline Alopecia & 1 & 0 & 1 & 0 & 2 & 0 & 1 & 0 & $5(19)$ & 0 \\
\hline Arthralgia & 1 & 0 & 1 & 0 & 1 & 0 & 2 & 0 & $5(19)$ & 0 \\
\hline Taste change $^{\mathrm{d}}$ & 1 & 0 & 0 & 0 & 1 & 0 & 2 & 0 & $4(15)$ & 0 \\
\hline Constipation & 1 & 0 & 1 & 0 & 1 & 0 & 1 & 0 & $4(15)$ & 0 \\
\hline Dyspepsia & 2 & 0 & 0 & 0 & 0 & 0 & 2 & 0 & $4(15)$ & 0 \\
\hline Myalgia & 1 & 0 & 3 & 0 & 0 & 0 & 0 & 0 & $4(15)$ & 0 \\
\hline $\begin{array}{l}\text { Palmar-plantar } \\
\text { erythrodysesthesia } \\
\text { syndrome }\end{array}$ & 0 & 0 & 1 & 0 & 0 & 0 & 2 & 0 & $3(12)$ & 0 \\
\hline
\end{tabular}

$A / C / P$ afatinib plus carboplatin plus paclitaxel, $A E$ adverse event, $A U C 5$ area under the concentration-time curve of $5 \mathrm{mg} / \mathrm{mL} \mathrm{min}, A U C 6$ area under the concentration-time curve of $6 \mathrm{mg} / \mathrm{mL} \min$

${ }^{+}$Grouped term (rash included reported preferred terms of rash, rash erythematous, rash pustular, dermatitis acneiform, skin fissures, blister and dermatitis; nausea/vomiting included reported preferred terms of nausea and vomiting)

${ }^{\text {a }}$ There were no treatment-related grade 4 or 5 events

${ }^{\mathrm{b}}$ Preferred term: mucosal inflammation

${ }^{\mathrm{c}}$ Preferred term: decreased appetite

${ }^{\mathrm{d}}$ Preferred term: dysgeusia

refractory NSCLC following $\geq 1$ line of chemotherapy, and whose tumors had progressed after disease control of $\geq 12$ weeks with erlotinib or gefitinib, and thereafter, afatinib. The combination of afatinib with paclitaxel significantly improved tumor response and PFS compared with paclitaxel alone in patients who had EGFR tyrosine kinase inhibitor (TKI)-resistant (including afatinib) disease [19]. Conversely, in the phase III IMPRESS study, gefitinib plus cisplatin and pemetrexed in patients with EGFR mutationpositive advanced NSCLC and acquired resistance to firstline gefitinib did not prolong PFS in the overall population versus cisplatin plus pemetrexed [20]. Indeed, OS was inferior in the experimental arm of this trial, although there was a suggestion of improved outcomes in patients lacking the T790M resistance mutation [21].

In the current study, the safety and clinical activity of two new afatinib combinations in patients with advanced solid tumors are presented. The RP2Ds of oral afatinib in these new combinations were defined as $40 \mathrm{mg} /$ day with carboplatin AUC6, and $20 \mathrm{mg} /$ day with carboplatin AUC5 and paclitaxel $175 \mathrm{mg} / \mathrm{m}^{2}$. These regimens may be of potential interest for further study, for example, in patients with squamous NSCLC; in selected populations with EGFR mutations; and, particularly for the combination of afatinib and carboplatin, in elderly populations and patients with an ECOG PS of $\geq 2$. 
Table 5 Pharmacokinetic parameters for carboplatin (measured as total platinum) and paclitaxel in the presence and absence of afatinib at the RP2D

\begin{tabular}{|c|c|c|c|c|c|c|c|c|}
\hline & \multicolumn{4}{|c|}{$\mathrm{A}(40 \mathrm{mg})+\mathrm{C}(\mathrm{AUC6})$} & \multicolumn{4}{|c|}{$\begin{array}{l}\text { A }(20 \mathrm{mg})+\mathrm{C}(\mathrm{AUC} 5)+\mathrm{P}(175 \mathrm{mg} / \\
\mathrm{m} 2)\end{array}$} \\
\hline & \multicolumn{2}{|c|}{ Cycle 1 (-afatinib) } & \multicolumn{2}{|c|}{ Cycle 2 (+ afatinib) } & \multicolumn{2}{|c|}{ Cycle 1 (-afatinib) } & \multicolumn{2}{|c|}{$\begin{array}{l}\text { Cycle } 2 \\
\text { (+ afatinib) }\end{array}$} \\
\hline & gMean & $\mathrm{gCV}, \%$ & gMean & $\mathrm{gCV}, \%$ & gMean & $\mathrm{gCV}, \%$ & gMean & $\mathrm{gCV}, \%$ \\
\hline \multicolumn{9}{|l|}{ Afatinib } \\
\hline $\mathrm{AUC}_{T, \mathrm{ss}}, \mathrm{ng} \mathrm{h} / \mathrm{mL}$ & - & & $\begin{array}{l}n=3^{\mathrm{a}} \\
465\end{array}$ & 91.8 & - & & $\begin{array}{l}n=7^{c} \\
326\end{array}$ & 60.4 \\
\hline$C_{\text {max }, \mathrm{ss}} \mathrm{ng} / \mathrm{mL}$ & - & & $\begin{array}{l}n=3 \\
44.2\end{array}$ & 9.76 & - & & $\begin{array}{l}n=7 \\
18.3\end{array}$ & 52.6 \\
\hline \multicolumn{9}{|l|}{ Total platinum } \\
\hline $\mathrm{AUC}_{0-24}, \mathrm{ng} \mathrm{h} / \mathrm{mL}$ & $\begin{array}{l}n=9 \\
76,800\end{array}$ & 16.9 & $\begin{array}{l}n=6^{\mathrm{a}} \\
75,700\end{array}$ & 23.6 & $\begin{array}{l}n=5^{\mathrm{b}} \\
69,700\end{array}$ & 12.4 & $\begin{array}{l}n=8^{\mathrm{c}} \\
65,400\end{array}$ & 20.9 \\
\hline$C_{\max } \cdot \mathrm{ng} / \mathrm{mL}$ & $\begin{array}{l}n=9 \\
21,100\end{array}$ & 31.0 & $\begin{array}{l}n=6 \\
19,600\end{array}$ & 26.8 & $\begin{array}{l}n=5 \\
16,200\end{array}$ & 22.9 & $\begin{array}{l}n=8 \\
17,800\end{array}$ & 15.8 \\
\hline Paclitaxel & & & & & & & & \\
\hline $\mathrm{AUC}_{0-23}, \mathrm{ng} \cdot \mathrm{h} / \mathrm{mL}$ & - & - & $\begin{array}{l}n=5^{\mathrm{b}} \\
10,400\end{array}$ & 21.8 & & & $\begin{array}{l}n=8^{\mathrm{c}} \\
10,700\end{array}$ & 32.2 \\
\hline$C_{\max ,} \mathrm{ng} / \mathrm{mL}$ & - & - & $\begin{array}{l}n=5 \\
3710\end{array}$ & 23.4 & & & $\begin{array}{l}n=8 \\
3620\end{array}$ & 50.9 \\
\hline
\end{tabular}

$A$ afatinib, $A E$ adverse event, $A U C_{0-23}$ area under the concentration-time curve of the analyte in plasma over 0-23 h, $A U C_{0-24}$ area under the concentration-time curve of the analyte in plasma over 0-24 $\mathrm{h}, A U C$ $T, s s$ area under the concentration-time curve of the analyte in plasma over a dosing interval, tau, at steady state, AUC5 area under the concentration-time curve of $5 \mathrm{mg} / \mathrm{mL} \mathrm{min}, A U C 6$ area under the concentration-time curve of $6 \mathrm{mg} / \mathrm{mL} \mathrm{min}, C$ carboplatin, $C_{\max }$ maximum measured concentration of the analyte in plasma, $C_{\max , s s} C_{\max }$ at steady state, $g C V$ geometric coefficient of variation, $g$ Mean geometric mean, $P$ paclitaxel, $P K$ pharmacokinetic, $R P 2 D$ recommended phase II dose

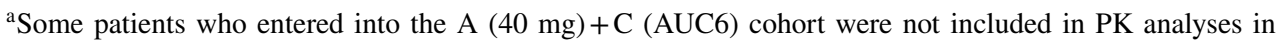
Cycle 2 due to AEs leading to treatment discontinuation, insufficient data availability for accurate PK evaluation or time violations in PK sampling

${ }^{\mathrm{b}}$ One patient who entered into the A $(20 \mathrm{mg})+\mathrm{C}$ (AUC5) $+\mathrm{P}\left(175 \mathrm{mg} / \mathrm{m}^{2}\right)$ cohort was not included in PK analyses in Cycle 1

${ }^{\mathrm{c}}$ Additional patients who received A $(30 \mathrm{mg})+\mathrm{C}(\mathrm{AUC} 5)+\mathrm{P}\left(175 \mathrm{mg} / \mathrm{m}^{2}\right)$ in Cycle 1 were subsequently moved to the A $(20 \mathrm{mg})+\mathrm{C}(\mathrm{AUC5})+\mathrm{P}\left(175 \mathrm{mg} / \mathrm{m}^{2}\right)$ dose cohort for Cycle 2 and were included in the PK analyses
Acknowledgements This study was supported financially by Boehringer Ingelheim, as well as by the UK Department of Health via the National Institute for Health Research (NIHR) Biomedical Research Centre (BRC) award to Guy's \& St Thomas' NHS Foundation Trust in partnership with King's College London and King's College Hospital NHS Foundation Trust (and NIHR Clinical Research Facility), and to The Institute of Cancer Research and Royal Marsden Hospital NHS Foundation Trust. King's College London and the Royal Marsden hold Experimental Cancer Medicine Centre grants. Katy Pelling, an employee of Boehringer Ingelheim International $\mathrm{GmbH}$ during the time of manuscript development, provided substantial contributions towards data assembly, analysis and interpretation, and manuscript writing. Medical writing assistance, funded by Boehringer Ingelheim, was provided by Laura Winton of GeoMed, an Ashfield Company, part of UDG healthcare plc.

Author contributions Conception and design: MU-F, JB, JS. Collection and assembly of data: MO, DS, JB, KT, MU-F, KP, JB, JS. Data analysis and interpretation: TAY, MU-F, XJ, SW, JB, JS. Provision of study material or patients: JB. Manuscript writing: MO, DS, JB, KT,
TAY, MU-F, KP, XJ, SW, JB, JS. Final approval of manuscript: MO, DS, JB, KT, TAY, MU-F, KP, XJ, SW, JB, JS.

\section{Compliance with ethical standards}

Conflict of interest J. Bhosle has received non-financial support from Boehringer Ingehleim. J. de Bono has received grants, personal fees and non-financial support from AstraZeneca, Genentech and Merck Sharp \& Dohme; personal fees from Pfizer Oncology, Janssen Oncology and Merck Serono; and grants and personal fees from Sanofi Aventis and GlaxoSmithKline. J. Spicer reports institutional receipt of honoraria from Boehringer Ingelheim. M. Uttenreuther-Fischer, K. Pemberton, X. Jin and S. Wiebe are employees of Boehringer Ingelheim International GmbH. All other authors report no potential conflicts of interest.

Ethical approval All procedures performed in studies involving human participants were in accordance with the ethical standards of the institutional and/or national research committee and with the 1964 Helsinki declaration and its later amendments or comparable ethical standards. 
Informed consent Informed consent was obtained from all individual participants included in the study.

Open Access This article is distributed under the terms of the Creative Commons Attribution 4.0 International License (http://creativeco mmons.org/licenses/by/4.0/), which permits unrestricted use, distribution, and reproduction in any medium, provided you give appropriate credit to the original author(s) and the source, provide a link to the Creative Commons license, and indicate if changes were made.

\section{References}

1. Solca F, Dahl G, Zoephel A et al (2012) Target binding properties and cellular activity of afatinib (BIBW 2992), an irreversible ErbB family blocker. J Pharmacol Exp Ther 343:342-350

2. Sequist LV, Yang JC, Yamamoto N et al (2013) Phase III study of afatinib or cisplatin plus pemetrexed in patients with metastatic lung adenocarcinoma with EGFR mutations. J Clin Oncol 31:3327-3334

3. Wu YL, Zhou C, Hu CP et al (2014) Afatinib versus cisplatin plus gemcitabine for first-line treatment of Asian patients with advanced non-small-cell lung cancer harbouring EGFR mutations (LUX-Lung 6): an open-label, randomised phase 3 trial. Lancet Oncol 15:213-222

4. Soria JC, Felip E, Cobo M et al (2015) Afatinib versus erlotinib as second-line treatment of patients with advanced squamous cell carcinoma of the lung (LUX-Lung 8): an open-label randomised controlled phase 3 trial. Lancet Oncol 16:897-907

5. Suder A, Ang JE, Kyle F et al (2015) A phase I study of daily afatinib, an irreversible ErbB family blocker, in combination with weekly paclitaxel in patients with advanced solid tumours. Eur J Cancer 51:2275-2284

6. Solca F, Baum A, Himmelsbach F et al (2006) Efficacy of BIBW 2992, an irreversible dual EGFR/HER2 receptor tyrosine kinase inhibitor, in combination with cytotoxic agents. Eur J Cancer Suppl 4:172

7. Spicer J, Irshad S, Ang JE et al (2017) A phase I study of afatinib combined with paclitaxel and bevacizumab in patients with advanced solid tumors. Cancer Chemother Pharmacol 79:17-27

8. European Medicines Agency (2015) Abraxane-European Public Assessment Report (summary). http://www.ema.europa.eu/docs/ en_GB/document_library/EPAR_-_Summary_for_the_public/ human/000778/WC500020431.pdf

9. Griggs JJ, Mangu PB, Anderson H et al (2012) Appropriate chemotherapy dosing for obese adult patients with cancer: American
Society of Clinical Oncology clinical practice guideline. J Clin Oncol 30:1553-1561

10. European Medicines Agency (2013) Giotrif $20 \mathrm{mg}$ film-coated tablets: Summary of Product Characteristics, Annex 1. http:// www.ema.europa.eu/docs/en_GB/document_library/EPAR_-Product_Information/human/00228.0/WC500152392pdf

11. Food and Drug Administration (2016) Gilotrif prescribing information. http://www.accessdata.fdagov/drugsatfda_docs/label /2016/201292s009lblpdf

12. EMC (2014) Carboplatin $10 \mathrm{mg} / \mathrm{ml}$ concentrate for solution for infusion. https://www.medicines.org.uk/emc/medicine/25716

13. Wind S, Schmid M, Erhardt J et al (2013) Pharmacokinetics of afatinib, a selective irreversible ErbB family blocker, in patients with advanced solid tumours. Clin Pharmacokinet 52:1101-1109

14. Murakami H, Tamura T, Takahashi T et al (2012) Phase I study of continuous afatinib (BIBW 2992) in patients with advanced nonsmall cell lung cancer after prior chemotherapy/erlotinib/gefitinib (LUX-Lung 4). Cancer Chemother Pharmacol 69:891-899

15. Herbst RS, Prager D, Hermann R et al (2005) TRIBUTE: a phase III trial of erlotinib hydrochloride (OSI-774) combined with carboplatin and paclitaxel chemotherapy in advanced non-small-cell lung cancer. J Clin Oncol 23:5892-5899

16. Gatzemeier U, Pluzanska A, Szczesna A et al (2007) Phase III study of erlotinib in combination with cisplatin and gemcitabine in advanced non-small-cell lung cancer: the Tarceva Lung Cancer Investigation Trial. J Clin Oncol 25:1545-1552

17. Wu YL, Lee JS, Thongprasert $S$ et al (2013) Intercalated combination of chemotherapy and erlotinib for patients with advanced stage non-small-cell lung cancer (FASTACT-2): a randomised, double-blind trial. Lancet Oncol 14:777-786

18. Dittrich C, Papai-Szekely Z, Vinolas N et al (2014) A randomised phase II study of pemetrexed versus pemetrexed + erlotinib as second-line treatment for locally advanced or metastatic nonsquamous non-small cell lung cancer. Eur J Cancer 50:1571-1580

19. Schuler M, Yang JC, Park K et al (2016) Afatinib beyond progression in patients with non-small-cell lung cancer following chemotherapy, erlotinib/gefitinib and afatinib: phase III randomized LUX-Lung 5 trial. Ann Oncol 27:417-423

20. Soria JC, Wu YL, Nakagawa K et al (2015) Gefitinib plus chemotherapy versus placebo plus chemotherapy in EGFR-mutationpositive non-small-cell lung cancer after progression on first-line gefitinib (IMPRESS): a phase 3 randomised trial. Lancet Oncol 16:990-998

21. Soria J-C, Kim S-W, Wu Y-L et al (Gefitinib/Chemotherapy vs Chemotherapy in EGFR Mutation-Positive NSCLC Resistant to First-Line Gefitinib: IMPRESS T790M Subgroup Analysis. In: 16th World Conference on Lung Cancer, Denver, CO, September 6-9 2015) Oral presentation 17.08 